\title{
Usage of Mobile Phone Applications and Its Impact
}

\section{on Teaching and Learning}

\author{
Nitza Davidovitch ${ }^{1} \&$ Roman Yavich $^{1}$ \\ ${ }^{1}$ Ariel University, Ariel, Israel \\ Correspondence: Roman Yavich, Ariel University, Ariel, Israel.
}

Received: December 3, 2017

Accepted: December 24, 2017

Online Published: January 4, 2018

doi:10.5430/ijhe.v7n1p1

URL: https://doi.org/10.5430/ijhe.v7n1p1

\begin{abstract}
This study continues studies on the concept of leisure as culture dependent - between tradition and modernity, while focusing on the usage of mobile phone applications and its impact on teaching and learning within a unique population. The study examined the association between having NetSpark on one's Smartphone and utilization of spare time among students who had or did not have the program installed. The assumption is that when the program is installed students will be more inclined to engage in non-internet related activities, such as spending time with friends, and when the program is not installed they will be more inclined to stay at home and be on the internet and will display less active life of other types. The research population included 120 9th-12th grade female students at a religious high school, aged 14-18. Half were students had had the NetSpark program installed on their phones, and half had not. The study used three questionnaires: a sociodemographic questionnaire, a questionnaire on Smartphone usage patterns, and a questionnaire on utilization of leisure time.

The research findings show no association between use of Smartphone applications and of the internet among students in whose phones the program had been installed versus those in whose phones it had not been installed. Secondly, no association was found between utilization of leisure time among students in whose phones the program was installed versus those in whose phones it had not been installed. Furthermore, no difference was found between the total time for which respondents had been using cellular phones of by religiosity, and no difference was found in the joint effect of religiosity + program on the variable daily duration of internet use. Moreover, no difference was found in use of cellular applications between respondents who had / did not have the NetSpark program installed, however use of cellular applications was found to be higher among respondents who ranked themselves less religious than among respondents who ranked themselves as highly religious. Finally, no difference was found in the utilization of leisure time (various activities) among respondents with different levels of religiosity.
\end{abstract}

Keywords: Teaching, Learning, Smartphone, Applications, Leisure, Jewish values, Tradition, Modernity

\section{Introduction}

Our previous research (Davidovitch \& Lazar, 2017; Davidovitch \& Soen, 2016, Davidovitch, 2014, Davidovich \& Yavich,2013) dealt with the concept of leisure as culture dependent - between tradition and modernity. We use leisure in terms of time, activity, state of mind, and Jewish values. In this study we focused on one activity that has many applications and examine changes in how leisure is conceived in Judaism, the differences among religious students who live between tradition and modernity. The article may have practical implications for imparting leisure behaviors, an educational challenge involving people's attitude to leisure.

The research population included 120 students in a girls' high school defined as religious, who declared that they are religiously observant. Religious society in Israel is diverse: some completely avoid use of tools that enable exposure to contents that conflict with religious principles, and some cope with the conflict. There are many different ways of life along this continuum (Davidovitch \& Lazar, 2017; Davidovitch \& Soen, 2016; Davidovitch, 2014). For this reason, it was interesting to focus on this population.

In the last decade, the internet has become an inseparable part of people's life - adults, teenagers, and children. It is used to locate information, for purposes of communication, entertainment, etc. Accordingly, the time devoted to this activity is rising, particularly among the young. With the benefits, awareness of the disadvantages of this tool has 
also risen. Problematic internet use might create various problems such as exposure to inappropriate contents for the user's age, mental distress, and addictions; all these are caused, among other things, by pathological internet use. Following awareness of the problems mentioned above, various programs have been developed, including NetSpark, which enables the blocking and/or filtering of internet systems. In Israel, the management at several schools decided to install the program in the mobile phones of most or some of the students. The purpose is, of course, ethical, and compatible with the school's ideology: maintaining students' safe use of the internet even when not at school. In the past, schools would block or filter websites on school computers, but it is now possible to filter inappropriate contents on the students' Smartphones, as use of the internet has expanded to this mode as well.

In recent years, the internet has become a major sphere of activity for children and teens, for purposes of information, interpersonal communication, as well as entertainment and social needs. On the internet teens listen to music, play computer games, search for information, speak with their friends, write about themselves, post their photographs, meet new people, respond to posts, and more. Namely, the virtual world has become an inseparable part of the physical world of children and teens. Therefore, they are spending a growing amount of time facing a computer screen. A survey held in the US revealed that children and teens devote about two and a half hours a day to the computer. In Europe, $60 \%$ of 9-16 year olds were found to use the internet every day or almost every day, for an hour and a half on average. In Israel, 92\% of teens aged 13-17 use the internet about two hours a day on average (Sasson, Erez \& Elgali, 2011).

Theories dealing with health risks show that perceiving behavior as dangerous is an important component in reducing involvement in this behavior. In addition, in adolescence, there is a rise in the significance of the peer group and its influence on the individual's behavior grows, therefore it is important to understand the worldview of children and teens in order to construct efficient prevention programs for reducing risk behaviors on the internet.

The rate of teens who use the internet is high, but still lower than in the US - 93\%. One partial explanation is the discrepancy between the internet use of young Jews and Arabs. Ninety three percent of 9-19 year olds in Israel make use of the internet (Refaeli, Arieli, \& Katzman, 2009).

\section{Use of the Internet}

In 2000, the office of President Bill Clinton published the report "Falling through the net: Defining the digital divide", which stated that over $50 \%$ of households in America have a computer and that access to the internet had grown significantly, from $26.2 \%$ in 1998 to $41.5 \%$ in 2000. Furthermore, global internet use had grown rapidly to approximately 581 million users in 2002, a rise of 463 million from the previous year. The more this electronic means continues to expand; we will probably see a rise in problem behaviors associated with its implementation.

Problematic internet use has been previously described variably, using terms such as computer addiction, internet addiction disorder, internet mania, and pathological internet use. Moreover, reports by many people with internet use problems have been published in recent years on the popular media and in the medical literature. Above all, problematic internet use might be categorized as an individual's inability to control his or her internet use, leading to distress and dysfunction in daily activities.

Many potential dangers are related to internet use and overuse. Problematic internet use is known as one's inability to control his or her internet use. The change causes stress and/or functional failure and has been described in the psychological literature as addiction to the internet and pathological internet use. Based on the fifth edition of the DSM, the definition is one of clear pathological dependency (Shapira, Goldsmith, Keck, Khosla, \& McElroy, 2000). The internet might be a platform for expressing a psychiatric illness (pathological addiction, paraphilia - deviant sexual behavior, and obsessive purchasing). Small systematic face-to-face psychiatric studies of people with internet use problems suggest high rates of comorbidity, including moods and anxiety disorders. In these studies, problematic internet use is also related to significant distress and dysfunction (Shapira, Lessig, Goldsmith, Szabo, Gold \& Stein, 2003). People with problematic internet use have reported high depressive symptoms. An online survey found depressive symptoms among 259 people classified as having an internet use problem. In addition, a study with 169 participants found an association between massive internet use and depression and loneliness, reduced contact with family members, and social deterioration (Shapira et al., 2000).

\section{Information on Smartphone Use}

Today, Smartphones are considered more than merely mobile phones. Thanks to the extensive functions they provide, Smartphones are not only a means of communication, rather they supply information in real time. In addition, they provide comfort to people's daily life and in many cases are also related to patterns of addiction.

While the population of adults "migrated" to the online environment, teens are growing up today in an era where the 
existence of the internet and its use are perceived as almost obvious. Moreover, they are digital natives who grew up surrounded by Smartphones and the Smartphone has become integrated in their lifestyle and identity. Therefore, teens more than adults are expected to be internet users. This assumption was confirmed in a study by the Pew Institute on intergenerational differences with regard to internet use among Americans. Hence, it is no surprise that in Israel as well the survey findings show a similar disparity, with $86 \%$ of teens using the internet versus $68 \%$ of adults (Refaeli, Ariely, and Katzman, 2009).

Smartphones have become a nearly inseparable part of the daily life of young Israelis. A survey conducted in 2015 found that the average age for receiving a Smartphone is 9.5. Further, the average duration of daily use at ages 12-17 is 3.4 hours. Girls were found to use their Smartphone more than boys. With regard to use of applications installed on the phone, $80 \%$ of 13-17 years olds were found to use the WhatsApp messages application for daily communication, $72 \%$ of Israeli teens use Instagram, and 55\% Snapchat (Lenhart, 2015). A study held at Haifa University showed that $94 \%$ of high school students in Israel access social networks in class. Only $4 \%$ make no use of Smartphones during class. The researchers stated that the students use their mobile phones in various ways - to surf the web and social networks, listen to music, take pictures, play games, and send text messages and photographs. According to the survey findings, there is almost no moment during class in which no students are using a Smartphone (Haifa University, 2012).

\subsection{Leisure}

A German study conducted with 14-92 year olds found that people with higher socioeconomic status have more access to the internet and are more inclined to use its many possibilities and applications (electronic mail, data search, purchases) in all age groups. A considerable proportion (9.3\%) reported negative consequences, such as excessive surfing, health compromises, as well as giving up leisure activities, entertainment, and social life (Beutel, Brähler, Glaesmer, Kuss, Wölfling, \& Müller, 2011).

Children and teens have almost unlimited access to the web, including technological instruments: computer, cellular phone, and i-pad. Use of technological instruments is becoming an inseparable part of daily life and is almost taken for granted. The internet is an inseparable part of this generation's environment and a place of entertainment, leisure, and means of communication with friends (Harari, Vidislavsky, \& Shemesh, 2001).

\subsection{NetSpark}

Almost all public schools in the US have internet access on school computers. Since the internet includes a variety of inappropriate material, this is a source of concern for many parents and teachers. In 2000, all public schools had access to the internet, about 98\%, and there were accepted use policies (AUPs) and varied technologies such as programs for blocking or filtering internet systems, "honor codes" for students, and supervision by the teaching staff in order to control students' access to inappropriate material. Between $95 \%$ and $100 \%$ of schools of all types took the AUP approach, 94\% reported access to internet surveillance by staff members, $74 \%$ reported that they use internet blocking or filters, and $64 \%$ had "honor codes". These data show that most schools (91\%) use more than one procedure or technology as part of their policy to maintain the safety of students' surfing at school (Well \& Lewis, 2006).

It is evident that, as in many other countries, in Israel as well teachers and parents ascribe much significance to supervising students' internet use at school and elsewhere. At present, with the technological developments and the rising use of Smartphones, it is not sufficient to supervise websites on school computers; rather the aim is to ensure safe use on students' Smartphones as well. For this purpose, a program called NetSpark was developed, to answer this need.

NetSpark has a dynamic capacity for graphic analysis, enabling it to constitute a filter solution that takes into account the continuous evolution of internet technology. The program uses automatic identification technologies to filter pictures on the internet, and provides full protection, particularly where there is no text to help decide whether to enable or block content. The "learning engine" examines unfamiliar pictures, analyzes picture components associated with those already classified in NetSpark's picture database, and is capable of determining whether the picture in its entirety is appropriate and can be approved or must be blocked. The graphics engine can distinguish between pictures that consist of pornography or adult content (for example, bathing suits worn on the beach, and also bathing suits or underwear sold on the internet, etc.). With more than a $99 \%$ chance of success, this is the most advanced technology on the market. NetSpark's breakthrough filter solutions let users take control of their internet experience, preserve access to the large range of resources on the web, while protecting them from inappropriate contents. NetSpark recognizes the enormous value of the internet as a useful tool and a source of knowledge, perceived as an 
important source for all members of modern society.

Despite the large potential, the internet also involves risks. Parents and teachers are increasingly searching for ways to protect their children and themselves from websites with inappropriate contents. Workplaces, schools, and other public places are also seeking a new solution that will enforce an accepted use policy and prevent abuse of the public internet they provide. NetSpark provides this solution. The company's unique technological approach examines automatically and filters content requests, evaluation of content on a page, in real time, and removes all inappropriate text or picture components before supplying the valuable content. This leaves a fully reconstructed page. NetSpark offers a unique filter that is capable of providing such results, and provides access to the maximal amount of content possible.

NetSpark provides several services - supervision of graphics, filtering - avoiding exposure to undesirable content without blocking the entire internet page, filtering content in real time - supervision and filtering of the page during use. Safety check of a website: The quantity of pornographic and inappropriate content found on safe websites is enormous, and should not be disregarded. The program gives users the ability to include filters, in order to ensure users' safety and access to appropriate content on the website, social media solutions - when coping with current-day problems (cyberbullying, hunters, and sexting), NetSpark enables supervision of profiles on social networks, chat messages, and blogs, in order to identify and respond to inappropriate content (NetSpark).

The purpose of this study was to examine whether there is a correlation between the existence of the NetSpark program on Smartphones and utilization of leisure time among students on whose phones the program has been installed versus those on whose phones the program has not been installed. Thus, we examined whether there are differences in the leisure habits of students on whose phones the program was or was not installed. The assumption was that when the program is installed students are more inclined to occupy themselves with activities unrelated to the internet, such as spending time with friends, physical activity, etc., and when the program is not installed they are more inclined to stay at home and use the internet. We focused on female students at the Ofra religious high school for girls, where the program was installed in students' cell phones by the management, and students of the same school on whose phones the program was not installed. We also examined the time devoted to internet use on Smartphones after installation of the NetSpark program, a program for blocking inappropriate contents. In addition, we examined whether the change enforced by the school by installing the program generated a change in students' use habits after school hours. Namely, do students use their leisure time for activities other than internet use on their Smartphone and other devices. Finally, we also sought to explore whether the variable of religiosity has an effect on the students' leisure activities.

Therefore our research hypotheses were:

1. A difference would be found in Smartphone use patterns, such that students on whose phones the program was installed will show less use of applications than students on whose phone the program was not installed.

2. An association would be found between installation of the NetSpark program that blocks inappropriate content and utilization of leisure time. Among students on whose phone the program is installed we will see varied leisure activities unrelated to internet use and for a longer period of time throughout the day, than among students on whose phone the program is not installed.

3. A difference would be found between internet use habits by religiosity. This means that the higher one's religiosity the lower the internet use, and the lower one's religiosity the higher the internet use.

4. A difference would be found between utilization of leisure time by religiosity. Namely, the higher one's religiosity the more leisure time will be devoted to activities other than internet use, and the lower one's religiosity the higher the internet use and the less additional activities.

5. A joint effect of religiosity and of the NetSpark program would be found on use of Smartphone applications.

6. A joint effect of religiosity and of the NetSpark program would be found on utilization of leisure time.

\section{Method}

\subsection{Participants}

The study included 120 9th-12th grade students at the Ofra high school for girls. The age range was 14-18 (mean 16). Half the respondents (60) were students on whose phone the NetSpark program was installed, and half the students (60) were those who did not have the program installed on their phone. The process of gathering the respondents was conducted in person at the school, on a voluntary basis, after receiving the approval of the school principal. 


\subsection{Instruments}

This study used three questionnaires: a sociodemographic questionnaire, a questionnaire on Smartphone use patterns, and a questionnaire on utilization of leisure time.

1. Sociodemographic questionnaire - a personal information questionnaire for respondents: sex, year of birth, religiosity.

2. Questionnaire on Smartphone use patterns -

2.1 The first part of this questionnaire is information on respondents' characteristics, including: three preliminary questions - was the program installed on the user's phone, years of cellular phone use, average duration of use per day.

2.2 In the second part of the questionnaire, respondents must answer 9 items that check the extent of their use of cellular applications. This questionnaire was taken from the study by David and Zipora (2011). The original questionnaire had 7 items, but since more cellular applications frequently used by teens were added in the years that passed from composition of the questionnaire, we added two items (use of WhatsApp and use of social networks). The current index includes 9 items, which the respondents were requested to rank on a 5-point Likert scale, from "not at all" (1) to "very much" (5).

3. Questionnaire on utilization of leisure time - This is an existing questionnaire, taken from the article by Cohen and Romi (2015). This is a self-report questionnaire that consists of 27 items, which check how much time respondents devote per day to the leisure activities listed. It includes 27 items ranked on a scale of 1-5 from "not at all" (1) to "a very significant amount of time" (2) (see Appendix 3).

\subsection{Procedure}

The questionnaires were administered face-to-face by the experimenter at the school, with responses kept anonymous. The purpose of the study was explained to all respondents, as well as the fact that their personal details would be kept confidential, that they are not obliged to participate, and that they can stop completing the questionnaire at any stage at will.

\section{Results}

Tables 1-2 present the reliability and the descriptive statistics of the research variables.

Table 1. Reliability and descriptive statistics of the research variables (mean, standard deviation, and range)

\begin{tabular}{lllll}
\hline & Reliability & Mean & $\begin{array}{l}\text { Standard } \\
\text { deviation }\end{array}$ & Range \\
\hline Use of Smartphone applications & 0.67 & 2.72 & 0.67 & $1.43-4.43$ \\
Utilization of leisure time & 0.75 & 2.48 & 0.40 & $1.44-3.56$ \\
\hline
\end{tabular}

Table 2. Descriptive statistics of the research variables (distribution of frequencies)

\begin{tabular}{llll}
\hline Questions & & $\mathrm{N}$ & $\%$ \\
\hline Is the NetSpark program installed on & Yes & 73 & 57.0 \\
your cellphone? & No & 55 & 43.0 \\
For how long have you had a & Between seven and nine years & 24 & 18.8 \\
cellphone? & Between one and three years & 90 & 70.3 \\
& Over nine years & 4 & 3.1 \\
How many hours do you use the & Less than one year & 10 & 7.8 \\
internet on average? & Between three and four hours & 35 & 27.3 \\
& Between one and two hours & 36 & 28.1 \\
& Between two and three hours & 35 & 27.3 \\
& Five or more hours & 22 & 17.2
\end{tabular}

According to the first research hypothesis, a difference would be found in use of cellular applications, use of cellular phones, daily duration of internet use, between respondents with NetSpark installed / not installed on their phones. In order to examine the research hypotheses, t-tests for independent samples were held. Table 3 describes the results of 
the analyses.

Table 3. Differences in use of cellular applications, use of cellular phones, daily duration of internet use, between respondents with NetSpark installed/not installed

\begin{tabular}{|c|c|c|c|c|c|}
\hline & \multicolumn{2}{|c|}{ NetSpark installed } & \multicolumn{2}{|c|}{$\begin{array}{l}\text { NetSpark not } \\
\text { installed }\end{array}$} & \multirow[t]{2}{*}{$\mathrm{t}(126)$} \\
\hline & M & $\mathrm{SD}$ & $\mathrm{M}$ & SD & \\
\hline Use of cellular applications & 2.67 & 0.69 & 2.80 & 0.64 & -1.06 \\
\hline Length of cellular phone use & 2.12 & 0.57 & 2.23 & 0.63 & -1.05 \\
\hline Daily duration of internet use & 2.39 & 1.08 & 2.25 & 1.04 & 0.74 \\
\hline
\end{tabular}

As evident from Table 3, the research hypothesis was not confirmed, and no significant difference was found in use of computer applications, use of cellular phones, daily duration of internet use, between respondents with NetSpark installed / not installed.

According to the second research hypothesis, a difference would be found in the utilization of leisure time between respondents with NetSpark installed / not installed. In order to examine the research hypothesis, a t-test for independent samples was conducted, finding that the research hypothesis was not confirmed, $t(126)=0.70, \mathrm{p}>.05$. Unlike the research hypothesis, there is no significant difference in the utilization of leisure time between respondents with NetSpark installed $(\mathrm{M}=2.50, \mathrm{SD}=0.44)$ or not installed $(\mathrm{M}=2.45, \mathrm{SD}=0.35)$.

According to the third research hypothesis, a joint effect of religiosity and of the NetSpark program would be found on the dependent variable of cellular phone use. For this purpose, a two-way analysis of variance was conducted.

As evident from Table 4, the NetSpark program has no main effect, $F(1,124)=0.08$, p>.05, i.e., no difference was found in length of cellular phone use between respondents with and without NetSpark. No main effect was found for religiosity, $\mathrm{F}(1,124)=0.56$, p>.05, i.e., no difference was found in length of cellular phone use between respondents with different levels of religiosity. Finally, there is no significant interaction effect, $F(1,124)=008, \mathrm{p}>.05$.

Table 4. Mean and standard deviation of length of cellular phone use by religiosity and NetSpark program

\begin{tabular}{|c|c|c|c|c|c|c|}
\hline & \multicolumn{2}{|c|}{ NetSpark installed } & \multicolumn{2}{|c|}{$\begin{array}{l}\text { NetSpark not } \\
\text { installed }\end{array}$} & \multicolumn{2}{|l|}{ Total } \\
\hline & M & $\mathrm{SD}$ & M & SD & $\mathrm{M}$ & $\mathrm{SD}$ \\
\hline $\begin{array}{l}\text { Respondents with low } \\
\text { religiosity }\end{array}$ & 2.33 & 0.51 & 2.33 & 0.57 & 2.33 & 0.50 \\
\hline $\begin{array}{l}\text { Respondents with high } \\
\text { religiosity }\end{array}$ & 2.10 & 0.58 & 2.23 & 0.64 & 2.15 & 0.61 \\
\hline Total & 2.12 & 0.57 & 2.23 & 0.63 & & \\
\hline
\end{tabular}

According to the fourth research hypothesis, a joint effect of religiosity and NetSpark would be found on the dependent variable of daily duration of internet use. For this purpose, a two-way analysis of variance was conducted.

As evident from Table 5, there is no main effect of the NetSpark program, $F(1,124)=0.59$, $p>.05$, i.e., no difference was found in daily duration of internet use between respondents with NetSpark installed/not installed. No main effect was found for religiosity, $\mathrm{F}(1,124)=2.70, \mathrm{p}>.05$, i.e., no difference was found in hours of internet use between respondents by religiosity. Finally, no significant interaction effect was found, $F(1,124)=0.26$, p>.05. 
Table 5. Mean and standard deviation of daily duration of internet use by religiosity and NetSpark

\begin{tabular}{lllllll}
\hline & \multicolumn{3}{c}{ NetSpark installed } & $\begin{array}{l}\text { NetSpark not } \\
\text { installed }\end{array}$ & Total & \\
& $\mathrm{M}$ & $\mathrm{SD}$ & $\mathrm{M}$ & $\mathrm{SD}$ & $\mathrm{M}$ & $\mathrm{SD}$ \\
\hline $\begin{array}{l}\text { Respondents with low } \\
\text { religiosity }\end{array}$ & 3.16 & 1.32 & 2.66 & 1.52 & 3.00 & 1.32 \\
$\begin{array}{l}\text { Respondents with high } \\
\text { religiosity }\end{array}$ & 2.32 & 1.05 & 2.23 & 1.02 & 2.28 & 1.03 \\
\begin{tabular}{l} 
Total \\
\hline
\end{tabular} & 2.39 & 1.08 & 2.25 & 1.04 & & \\
\hline
\end{tabular}

According to the fifth research hypothesis, a joint effect of religiosity and NetSpark would be found on the dependent variable of use of cellular applications. For this purpose, a two-way analysis of variance was conducted.As evident from Table 6, there is no main effect of the NetSpark program, $F(1,124)=1.13$, p>.05, i.e., no difference was found in use of cellular applications between respondents with NetSpark installed/not installed. A main effect was found for religiosity, $\mathrm{F}(1,124)=18.91$, $\mathrm{p}>.001$, i.e., use of cell phone applications was higher among respondents with low religiosity than among respondents with high religiosity. Finally, no significant interaction effect was found, $\mathrm{F}(1,124)=0.22$, $\mathrm{p}>.05$.

Table 6. Mean and standard deviation of use of cellular applications by religiosity and NetSpark

\begin{tabular}{lcclccc}
\hline & \multicolumn{5}{c}{ NetSpark installed } & \multicolumn{2}{l}{$\begin{array}{l}\text { NetSpark not } \\
\text { installed }\end{array}$} & Total & \\
& $\mathrm{M}$ & $\mathrm{SD}$ & $\mathrm{M}$ & $\mathrm{SD}$ & $\mathrm{M}$ & $\mathrm{SD}$ \\
\hline $\begin{array}{l}\text { Respondents with low } \\
\text { religiosity }\end{array}$ & 3.50 & 0.70 & 3.85 & 0.49 & 3.61 & 0.63 \\
$\begin{array}{l}\text { Respondents with high } \\
\text { religiosity }\end{array}$ & 2.60 & 0.65 & 2.73 & 0.60 & 2.66 & 0.63 \\
\begin{tabular}{l} 
Total \\
\hline
\end{tabular} & 2.67 & 0.69 & 2.80 & 0.64 & & \\
\hline
\end{tabular}

According to the sixth research hypothesis, a joint effect of religiosity and of NetSpark would be found on the dependent variable of utilization of leisure time. For this purpose, a two-way analysis of variance was conducted.

As evident from Table 7, there is no main effect of the NetSpark program, $F(1,124)=0.07$, p >.05, i.e., no difference was found in utilization of leisure time between respondents with NetSpark installed/not installed. No main effect was found for religiosity, $F(1,124)=0, p>.05$, i.e., no difference was found in the utilization of leisure time between respondents by religiosity. Finally, no significant interaction effect was found, $F(1,124)=0.005$, $p>05$.

Table 7. Mean and standard deviation of utilization of leisure time by religiosity and NetSpark

\begin{tabular}{llccccc}
\hline & \multicolumn{5}{c}{ NetSpark installed } & \multicolumn{2}{c}{$\begin{array}{l}\text { NetSpark not } \\
\text { installed }\end{array}$} & Total & \\
& $\mathrm{M}$ & $\mathrm{SD}$ & $\mathrm{M}$ & $\mathrm{SD}$ & $\mathrm{M}$ & $\mathrm{SD}$ \\
\hline $\begin{array}{l}\text { Respondents with low } \\
\text { religiosity }\end{array}$ & 3.50 & 0.70 & 3.85 & 0.49 & 3.61 & 0.63 \\
$\begin{array}{l}\text { Respondents with high } \\
\text { religiosity }\end{array}$ & 2.60 & 0.65 & 2.73 & 0.60 & 2.66 & 0.63 \\
\begin{tabular}{l} 
Total \\
\hline
\end{tabular} & 2.67 & 0.69 & 2.80 & 0.64 & & \\
\hline
\end{tabular}

\section{Discussion}

Our previous research (Davidovitch \& Lazar, 2017; Davidovitch \& Soen, 2016; Davidovitch, 2014) dealt with the concept of leisure as culture dependent - between tradition and modernity. We use leisure in terms of time, activity, state of mind, and Jewish values. In this study we focused on one activity that has many applications and examined changes in how leisure is conceived in Judaism, the differences among religious students who live between tradition and modernity. The article may have practical implications for imparting leisure behaviors, an educational challenge involving people's attitude to leisure. 
The research population included 120 students in a girls' high school defined as religious, who declared that they are religiously observant. Religious society in Israel is diverse: some completely avoid use of tools that enable exposure to contents that conflict with religious principles, and some cope with the conflict. There are many different ways of life along this continuum (Davidovitch \& Lazar, 2017; Davidovitch \& Soen, 2016; Davidovitch, 2014). For this reason, it was interesting to focus on this population.

The purpose of the current study was to examine whether there is an association between having the NetSpark program on one's Smartphone and utilization of one's leisure time, among students who had / did not have NetSpark installed on their phones.

It is evident that despite our initial assumption, this study showed no association between the installation of internet blocking programs, use of cellular applications, and utilization of leisure time among students who had / did not have NetSpark installed on their phones. In addition, no difference was found in usage with regard by religiosity.

The first research hypothesis was not confirmed and no significant difference was found in use of computer applications, use of cellular phones, and daily duration of internet use between respondents who had / did not have the NetSpark program installed. In addition, when examining the second research hypothesis, no significant difference was found in the utilization of leisure time among respondents who had the NetSpark program.

Moreover, in response to the third research hypothesis as well no difference was found in length of cellular phone use between respondents with and without NetSpark, i.e., no difference was found in length of cellular phone use between respondents by religiosity. In addition, in response to the fourth research hypothesis too no difference was found in daily duration of internet use between respondents with and without NetSpark. Also with regard to the fifth hypothesis, no difference was found in use of Smartphone applications between respondents who had / did not have NetSpark. A main effect of religiosity was found, however, i.e., use of Smartphone applications was higher, among less religious respondents than among more religious respondents. Finally, in contrast to the sixth research hypothesis, no difference was found in the utilization of leisure time between respondents with / without NetSpark.

All the research hypotheses are based on the research literature, as stated in our previous studies. The fact that only one hypotheses was proved indicates that the leisure patterns of young religious people are becoming more similar to those that exist in modern society in general.

In religious society it is forbidden to worship idols and for this reason, in many respects, modern leisure clashes with the values of religious society. Religious society exists within an open and modern society and tries to make adjustments in order to remain part of the changing world. In contrast, there is a limit to the flexibility desired and utilized by this society. The most significant educational challenge for religious society in the twenty-first century is the need to cope with the interplay between tradition and modernity. This relationship exists in a large range of areas, however in light of the role of leisure in young people's lives, this is one of the most essential and major areas in their moral education. Consequently, how this sector will educate its future generation to spend its leisure time will dictate their entire world of values.

The education system has acknowledged and should continue more vigorously to pursue its role to help the individual, the family, the community, and society, to secure quality of life and well-being through the informed use of leisure activities by developing moral, physical, emotional, intellectual, and social aspects of leisure that align with the educational goals of Israel and Jewish heritage in the twenty-first century.

\section{Contribution of the Study}

The study contributed by illuminating the subject of internet use and utilization of leisure time. Evidently, although most of the hypotheses were found insignificant, we did manage to find higher use of cellular applications among respondents with low religiosity than among respondents with high religiosity. This shows that respondents with low religiosity make more use of their Smartphone, spend more time online, and devote more time to this occupation than students who reported being more religious. The finding may show that religiosity does have a certain effect on respondents' choice to invest more or less time in use of their Smartphone.

A study conducted with male students could illuminate boys' use of Smartphones and the association between installation of the program and utilization of leisure time. In addition, a study performed in a different method than by self-report questionnaires could possibly reach more accurate results. Moreover, a study conducted at secular schools could provide more information as well as a comparison between secular and religious schools. A large study performed in several different schools would also be able to provide additional information, as the sample would be larger, and the larger the sample the closer to the mean among the entire population. 
This study examined the relationship between installing NetSpark on Smartphones and utilization of one's leisure time, among students who had / did not have the program installed. Moreover, the religiosity variable was examined as well. In contrast to the research hypotheses, the results showed no difference between respondents who had / did not have NetSpark installedת with regard to use of cellular phones and their applications. This was also found with regard to utilization of leisure time. In fact, in contrast to our first assumption that students who have had the program installed devote more time to pastimes other than Smartphone applications, there seems to be no real difference between those who have the program and those who don't. One thing that was confirmed, however, is that when religiosity is low use of cellular phones was found to be higher than among respondents with low religiosity.

\section{Acknowledgments}

Tzori Ralbag and Rakefet Livne

\section{References}

Beutel, M. E., Brähler, E., Glaesmer, H., Kuss, D. J., Wölfling, K., \& Müller, K. W. (2011). Regular and problematic leisure-time Internet use in the community: results from a German population-based survey. Cyberpsychology, Behavior, and Social Networking, 14(5), 291-296. https://doi.org/10.1089/cyber.2010.0199

Cohen, A. \& Romi, S. (2015). Leisure among youth in Israel: Non-formal education, school climate, violence, risk of dropping out and well-being. Ramat Gan: Bar Ilan University. [Hebrew]

David \& Tzipora (2011). Use of cellular telephones: Jewish teens versus Bedouin teens in Israel. Beer Sheva: Ben Gurion University. [Hebrew]

Davidovitch, N. \& Lazar, A. (2017). The Sabbath, the synagogue and leisure culture: Jewish tradition and modernity. US-China Education Review A \& B, 7(3), 159-165. David Publishing Compny Limited. https://doi.org/10.17265/2161-6248/2017.03.005

Davidovitch, N. \& Soen, D. (2016). Leisure in the twenty-first century: The case of Israel. Israel Affairs, 22(2), 492-511. https://doi.org/10.1080/13537121.2016.1140347

Davidovitch, N. (2014). The concept of leisure as culture-dependent - between tradition and modernity. Cultural and Religious Studies, 2(6), 307-317. https://doi.org/10.17265/2328-2177/2014.06.001

Davidovich, N., \& Yavich, R. (2013). Course websites and their contribution to students evaluation of instructors and their courses. Research Journal of Management Sciences, 2(3), 1-7.

Harari, L., Vidislavsky, M. \& Shemesh, D. (2001). The way to a safe space on the internet. Journal for Promoting Leadership, Professionalism, and Excellence in the School Administration in Elementary Education. Ministry of Education. [Hebrew]

Lenhart, A. (2015). Teens, social media \& technology overview 2015. Pew Research Center, 9.

NetSpark website. Accessed 14 March 2017 from http://www.netspark.com/?a=technologies/graphic_inspection

Shapira, N. A., Goldsmith, T. D., Keck, P. E., Khosla, U. M., \& McElroy, S. L. (2000). Psychiatric features of individuals with problematic internet use. Journal of Affective Disorders, 57(1), 267-272. https://doi.org/10.1016/S0165-0327(99)00107-X

Rafaeli, S., Ariel, Y. \& Katzman, M. (2010). Online youth: Internet use and purchasing patterns. Ministry of Trade and Employment. [Hebrew]

Sasson, H., Erez, R. \& Elgali, Z. (2011). Risks on the web: Adolescents' perceptions and coping mechanisms. The 4th Knowledge Cities World Summit, 350-356. [Hebrew]

Shapira, N. A., Lessig, M. C., Goldsmith, T. D., Szabo, S. T., Lazoritz, M., Gold, M. S., \& Stein, D. J. (2003). Problematic internet use: proposed classification and diagnostic criteria. Depression and Anxiety, 17(4), 207-216. https://doi.org/10.1002/da.10094

Survey on use of cell phones in class (2012). Haifa University. [Hebrew]

Wells, J., \& Lewis, L. (2006). Internet access in US public schools and classrooms: 1994-2005. National Center for Education Statistics. 